\title{
Evolução humana - inteligência como determinante
}

\author{
Prof. Dr. Fabiano de Abreu Agrela Rodrigues ${ }^{1}$ \\ deabreu.fabiano@gmail.com
}

\section{RESUMO}

A inteligência é uma faculdade humana difícil de ser definida. Essa definição varia entre especialistas que a estudam em acordo com suas áreas sejam elas biológicas, neurológicas ou psicológicas. Ao longo dos anos, estudando a evolução humana, foi possível definir certos parâmetros para o que vem a ser inteligência e como o cérebro e as características dos meio têm papéis fundamentais na sua formação. O presente estudo tem o objetivo de apresentar a inteligência humana à luz da evolução do homem.

Palavras-chave: evolução; inteligência; cérebro.

${ }^{1} \mathrm{PhD}$, neurocientista com formações também em neuropsicologia, biologia, história e antropologia deabreu.fabiano@gmail.com - Centro de Pesquisas e Análises Heráclito - Castelo de Paiva - Aveiro Portugal 


\title{
Human evolution - intelligence as determinant
}

\begin{abstract}
Intelligence is a human faculty that is difficult to define. This definition varies among specialists who study it according to their areas, whether biological, neurological, or psychological. Throughout the years, studying human evolution, it has been possible to define certain parameters for what intelligence is and how the brain and the characteristics of the environment play fundamental roles in its formation. The present study has the objective of presenting human intelligence in accordance with human evolution.
\end{abstract}

Keywords: evolution; intelligence; brain.

Artículo recibido: 05 octubre. 2021 Aceptado para publicación: 02 noviembre 2021 Correspondencia: deabreu.fabiano@gmail.com Conflictos de Interés: Ninguna que declarar 


\section{INTRODUÇÃO}

Para entender a evolução humana é preciso de uma ciência multidisciplinar. Tudo começa com a descoberta de fósseis e seu estudo é feito com a ajuda de outras ciências como a genética, a paleontologia e a ecologia sendo possível entender as transformações humanas ao longo da história.

A evolução é entendida como aspectos biológicos e comportamentais que vão se transformando ao longo de tempo, de acordo com o meio ambiente e que são passados de maneira hereditária para os futuros membros da espécie.

O DNA tem papel importante na hereditariedade. Nele estão contidas todas as informações genéticas necessárias para o desenvolvimento e funcionamento dos seres vivos e são transmitidas de uma geração para outra. O estudo de sua estrutura possibilitou que geneticistas encontrassem traços da ancestralidade comum entre todos os seres vivos (The Human Journey, 2021).

Presente no núcleo de cada célula do organismo, o DNA possui na sua composição bases nitrogenadas (citosina, timina, adenina, guanina) e sua capacidade mais impressionante é a de copiar a si mesmo permitido que os organismos cresçam e se reproduzam. (Simms) Muitos pesquisadores buscam entender se a genética e a inteligência estão conectadas. Testes feitos com o DNA de pessoas sem conexão umas com as outras, mas com similaridades no sua genética e similaridades em seus testes cognitivos, mostraram que a genética é um fator importante a ser observado no desenvolvimento da inteligência (Deary, 2021).

O meio também é descrito como fundamental para o processo evolutivo. A necessidade de se adaptar a florestas, desertos, áreas montanhosas, áreas fluviais e a necessidade de buscar alimento e viajar para outras áreas provocaram mudanças impressionantes no corpo humano como a mudança das mãos e dedos, a capacidade de andar com as duas pernas, o aumento do tamanho do cérebro e o desenvolvimento de suas estruturas internas (Tuttle, 2021).

A inteligência pode ser observada como um aspecto evolucionário, porém, uma vez que fatores externos e internos influenciam na sua constituição, defini-la se torna um desafio. Quando se observa as diferentes formas de vida, cada uma delas possui inteligências diferentes moldadas por diferentes ambientes. Seja meio ambiente, a genética ou a 
aglutinação de ambos, diferentes áreas definem, a sua maneira, o que é inteligência (Weder, 2020).

\section{EVOLUÇÃO E INTELIGÊNCIA}

A evolução humana é um lento processo de adaptação e transformação. É possível traçar ao longo do tempo as mudanças internas e externas do homem e sua capacidade de sobreviver e se adaptar ao meio hostil. Sendo assim, como o homem chegou a este estágio e quais aspectos culturais e biológicos foram fundamentais para permitir que o homem ser tornasse único entre todos os seres vivos?

O processo adaptativo, tanto cultural quanto fisiológico do homem foi resultado de vários fatores amplamente estudados ao longo dos anos. Segundo pesquisadores a capacidade de criar ferramentas com pedra, de criar abrigos, de produzir alimentos cada vez mais em maior escala, foram alguns dos avanços tecnológicos que ao transcorrer dos anos permitiu a evolução. Entre todos esses avanços tecnológicos, a capacidade de manusear o fogo, segundo muitos pesquisadores foi fundamental para a espécie humana, sua sobrevivência e seu domínio sobre outros seres vivos (Sandgathe, 2017).

O domínio do homem sobre o fogo, em um período histórico ainda não completamente definido entre especialistas, mais provável no período paleolítico, permitiu que o homem sobrevivesse e se adaptasse a baixas temperaturas, se protegesse contra animais selvagens, melhorasse a sua alimentação, criasse armas, instrumentos, prolongasse os dias, entre outros (MacDonald, 2017).

O fogo se tornou uma necessidade para a vida humana. Seu domínio possibilitou o estabelecimento do homem em uma localidade específica e a possibilidade da construção de comunidades. Ele atua em diferentes esferas sociais, na sua adaptação, criação de tecnologias e produção alimentar sendo possível ainda ver seus vestígios até mesmo em ideologias e religiões com culturas inteiras formada envolta da sua existência (Chazan, 2017)

Para Laland (2017) a formação da cultura é algo único entre os seres humanos. A capacidade para a criação de uma sociedade cada vez mais complexa, formada por leis, códigos morais, códigos linguísticos e instituições, permitiram o avanço das funções cognitivas.

A criação e utilização de instrumentos, a criação de comidas e músicas ligadas a uma tradição, memorização de fatos passados, imitação de comportamento e a capacidade para 
ensinar - algo não encontrado em nenhuma outra espécie-, possibilitou o desenvolvimento das capacidades mais surpreendentes do homem: tecnologia, cooperação, linguagem e inteligência.

\subsection{A Inteligência}

Gerhard Roth (2015) afirma que há entre muitos os biólogos uma visão de que a evolução cerebral, principalmente o desenvolvimento das redes de neurônios, foi a responsável por permitir que o cérebro chegasse a esse estado evolutivo que nos tornam únicos entre os seres vivos e que esse é apenas um dos vários estágios para formação da inteligência. Essa inteligência permitiu aos humanos se adaptarem ao longo da história e a sobreviverem sob as mais extraordinárias adversidades.

Entre os humanos, a inteligência é definida como a capacidade para abstrações, formação da memória, planejamento, entendimento, resolução de problemas, comunicação e aprendizagem.

Entretanto, ainda há entre especialistas, uma divergência quanto a real e mais completa definição da inteligência. São muitas as diferentes teorias que buscam determinar os componentes importantes para a sua concepção. Entre as várias teorias estão:

- Fator $\mathbf{g}$ : Proposta por Charles Spearman é a teoria geral da inteligência e é composta por dois fatores; a capacidade de resolver problemas e a capacidade de adquirir conhecimento.

- Teoria das inteligências múltiplas: proposta Henry Gardner, afirma que a inteligência abrange várias áreas e esta relacionada a diferentes habilidades como: lógico - matemática, espacial, musical, linguística, corporal, intrapessoal, interpessoal.

- Aptidões Primárias: proposta por Louis Thurstone, identifica setes aptidões primárias: raciocínio, fluência, aptidão numeral e espacial, compreensão verbal, velocidade perceptiva e memória.

- Teoria Triárquica da inteligência: proposta pó Robert Steinberg, define três fatores fundamentais para inteligência: Inteligência analítica, criativa e prática (Cherry, 2019).

- Inteligência DWRI: proposta por Fabiano de Abreu Rodrigues, consiste em uma inteligência determinante que desenvolve todas as demais inteligências. A priori 
genética com a região frontal do cérebro mais desenvolvida, é um precursor para desenvolver as demais inteligências já que esta região é de controle e tomada de decisões e pessoas com essa região mais desenvolvidas apresentam uma personalidade curiosa e buscam mais conhecimento e acabam por desenvolver as demais regiões relacionadas a inteligência caso não tenha nuances que prejudiquem o desenvolvimento específico (Rodrigues, 2021).

Entre todas as definições que são apresentadas é possível apontar duas características fundamentais: a habilidade em uma tarefa específica para alcançar um objetivo e a habilidade de adaptação e generalização. Essa generalização é a que permite que as pessoas lidem com situações e tarefas totalmente novas e se adaptem para cumpri-las se utilizado de informações e habilidades obtidas em situações anteriores (Chollet, 2019).

\subsection{Adaptação}

De acordo com Johnson et al (2015) a adaptação ocorre em função da interação entre as características gerais do ambiente e as circunstâncias individuais com o que indivíduo nasce. Por essa razão é possível observar desde o nascimento que o cérebro busca reter e processar as informações do ambiente, e desenvolver competências necessárias a sobrevivência.

Uma das mais significativas adaptações durante a evolução foi o bipedalismo humano.

Diversos animais possuem a capacidade para andar sobre duas patas, porém nenhum o faz como o ser humano. Essa evolução provocou mudanças anatômicas singulares. Levantar, alcançar objetos e alimentos em lugares altos, se locomover mantendo as mãos livres, se levantar, andar e correr possibilitaram ao homem andar sobre os dois pés, verticalizando a sua coluna e transferindo sua massa corpórea da pélvis para as pernas, pés e dedos diferenciando o homem dos outros primatas (Tuttle, 2021).

A anatomia dos pés e das mãos também se modificou. Os pés do seres humanos apresentam dedos mais curtos, osso do calcanhar maior e os arcos longitudinais e transversais melhores desenvolvidos. Tais mudanças surgiram a partir da demanda por caminhadas mais longas e corridas e da não necessidade de locomoção arborícola (Holowka, 2018). 

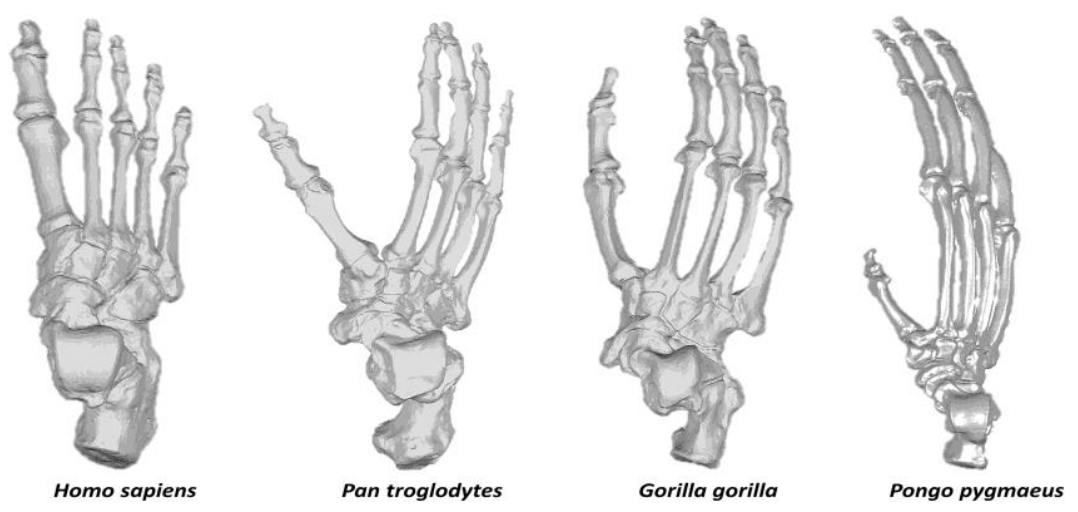

Fonte: American Journal of Physical Anthropology

Diferente dos outros primatas, a mão humana possui articulações mais flexíveis, palmas e dedos mais curtos, com polegares mais fortes e com maior mobilidade. Tais características permitiram que o homem segurasse objetos tanto com a ponta dos dedos quanto envolvendo-os com a mão toda aumentando a força e a precisão (Morgan, 2013).
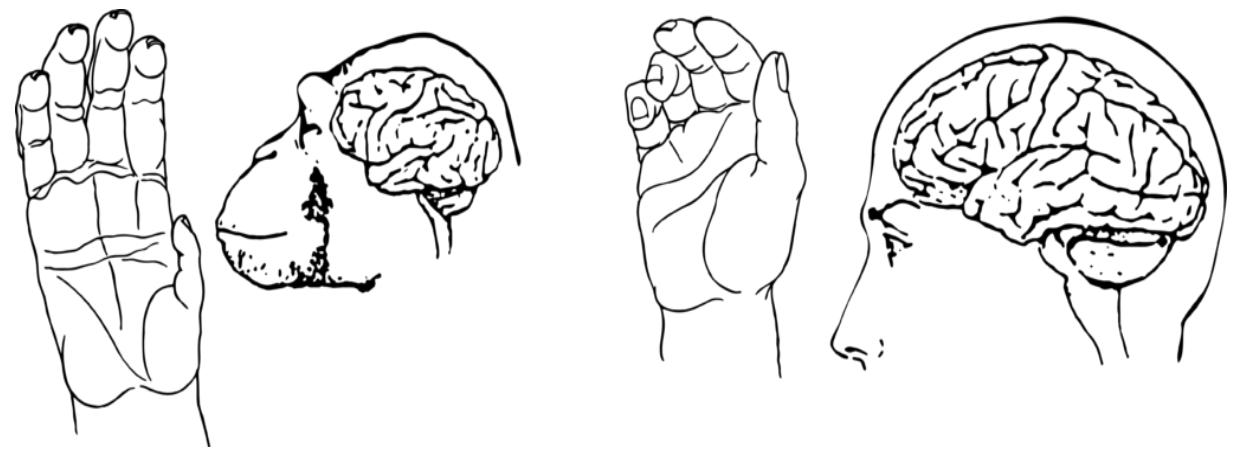

Fonte: Sergio Almécija. The Hand. 2021. http://www.sergioalmecija.com/the-hand/

\subsection{O Homem e os animais}

O homem é um ser único entre todas as espécies da natureza. Entretanto, cérebro humano não é o maior entre todos os seres vivos, nem mesmo possui a maior quantidade de neurônios. Mesmo sendo um ser tão singular, o homem apresenta tanto similaridades quanto divergências em relação a outros seres vivos quanto as suas habilidades cognitivas e inteligência..

O processo evolutivo da espécie permitiu o desenvolvimento da linguagem, imaginação, capacidade para criar, inventar e construir. Para Herculano-Houzel (2009) o cérebro humano não é especial em relação à composição celular, não possui os 100 bilhões de neurônios, números amplamente divulgados erroneamente, e seu córtex possui aproximadamente $19 \%$ dos neurônios do cérebro, quantidade similar em outros mamíferos. 
Apesar das diferenças fundamentais, homens e ratos têm similaridades genéticas que permitem, por exemplo, pesquisas com ratos para compreender o cérebro humano, estudar uma doença, testar medicamentos e entender melhor a biologia dos homens (Robert, 2016). Além da similaridade dos genes, ratos são capazes de se comportar de maneira bondosa ajudando outros membros da espécie (Sato, 2015).

Um estudo feito com 120 espécies de mamíferos por Yaniv Assaf et al (2020) mostrou que os cérebros dos humanos e dos mamíferos apresentam a mesma eficiência em relação à transferência de informações de um neurônio para outro para todas as áreas do cérebro através das sinapses. Essa eficiência não é nem maior entre humanos e nem depende do tamanho e da estrutura do cérebro (Bird, 2020).

Outro, feito por Inoue e Matsuzawa (2007), mostra que chimpanzés possuem uma melhor memória fotográfica em relação aos humanos em se tratando de números. Durante testes feitos, eles acertavam rapidamente a sequência de números arábicos. Entre humanos e chimpanzés, os mais semelhantes entre os primatas, o cérebro humano é três vezes maior e possui duas vezes mais neurônios no córtex cerebral (Mora-Bermúdez, 2016).

Para Gomés-Robles et al (2015) as diferenças cerebrais significativas entre humanos e chimpanzés podem ser traçadas no caminho evolutivo que cada uma das espécies tomou após se afastarem de seu ancestral comum. A cultura e a socialização são a chave para o desenvolvimento humano e isso se reflete no comportamento de chimpanzés criados entre homens, o que permite que estes animais tenham habilidades cognitivas superiores em relação aos que vivem na natureza. Durante pesquisas, foi observado que o cérebro do chimpanzé já se encontra "completo" desde o nascimento, enquanto o do ser humano se forma desde a infância através da aprendizagem e das sinapses.

Mesmo com tantos fatores que unem a espécie humana com outros animais, ainda assim muitas diferenças podem ser encontradas devido o gene, a capacidade de adaptação e a plasticidade do cérebro. David Premack (2007) comparou humanos e animais no que se refere a alguns elementos da inteligência. Para ele o aprendizado dos animais está relacionado à adaptação e sobrevivência enquanto que os humanos aprendem por razões diferentes para alcançar diferentes objetivos.

$\mathrm{O}$ ato de ensinar entre os animais, por exemplo, possui apenas um objetivo específico, sobrevivência. Os adultos da espécie ensinam os filhotes a caçar, morder, envenenar para conseguir alimento. Já os humanos ensinam por diversos motivos em diferentes domínios 
seja para aprender uma habilidade fundamental, entender padrões de comportamento aceitáveis, principalmente se tratando de crianças ou, simplesmente, por estética.

Outros elementos estudados mostraram que os animais, entre eles os primatas, carecem de habilidades cognitivas importantes impedindo a equiparação entre os cérebros humano e animal em diferentes âmbitos. Eles não são capazes de elaborar uma linguagem complexa (mesmo os chimpanzés que aprendem linguagem de sinais não são capazes de ter expressões faciais), não desenvolveram linguagem escrita e não há evidências claras que os animais tenham noção de causa e efeito.

As adversidades naturais moldaram a biologia das espécies. O córtex cerebral dos animais é transformado através das informações do ambiente captadas pelos sentidos. Essas transformações definem as características cerebrais e motoras de cada espécie, visão, audição, olfato, tato, velocidade, dentição, pele, garras etc.

Um estudo com 1.400 espécies de mamíferos existentes e extintos verificou a relação entre o tamanho do corpo e do cérebro durante e suas transformações no período de 150 milhões de anos. Esse estudo revelou que essa relação ocorreu de diferentes maneiras em diferentes espécies. Os macacos de grande porte têm geralmente uma regularidade quanto ao tamanho do cérebro e do corpo, diferente os hominídeos que apresentaram uma diminuição dos corpos e um aumento no tamanho do cérebro.

Elefantes, baleias e golfinhos também apresentaram transformações cerebrais ao longo do tempo. Elefantes aumentaram o tamanho do cérebro com o aumento do tamanho dos corpos. As baleias tiveram mudanças menos perceptíveis se mantendo não somente como o maior mamífero (baleia azul) mas também como o maior cérebro. E no caso dos golfinhos, estes mostraram um aumento no o tamanho do cérebro e uma diminuição do tamanho do corpo.

Para os pesquisadores, as diferentes trajetórias evolutivas entre os mamíferos é um reflexo do ambiente, principalmente das mudanças climáticas e de dois cataclismo ocorridos durante a história. As maiores mudanças encontradas em relação ao desenvolvimento físico e cerebral dos animais ocorreram após o fim do período cretáceo e foram mais influenciadas pelo clima quente do paleogeno (Smaers, 2021).

Em relação aos carnívoros, se entendia que estes possuíam maior desenvolvimento cognitivo e maior quantidade de neurônios no córtex cerebral devido à necessidade de aperfeiçoar técnicas de caça para alimentação. Entretanto, o que se descobriu é que a 
quantidade de neurônios dos carnívoros é balanceada com o custo metabólico envolvido, ou seja, o gasto de energia é maior. Seguindo a relação entre a quantidade de massa corporal e quantidade de neurônios, carnívoros de grande porte precisam tanto de maior quantidade de comida quanto de maior quantidade de descanso.

Seguindo, também, essa relação entre tamanho do corpo e quantidade de neurônios, animais domésticos como cachorros e gatos apresentam diferenças em relação um e outro. Cachorros têm cérebros maiores e neurônios em maior quantidade do que os gatos. Raças como Golden Retriever possuem 46\% mais quantidade de neurônios do que cachorros pequenos (Jardim-Messeder, 2017).

De acordo com DeCasien et al ( 2017) a dieta dos animais também é fator para as diferenças entre os cérebros. Um estudo feito na New York University em 140 espécies de primatas divididos em quatro grupos - folívoros, omnivoros, folívoros e frugíveros e frugíveros - mostrou que os frugíveros/folíveros e omníveros possuem um cérebro maior do que os exclusivamente folíveros e que o frugíveros possuem o cérebro um pouco maior que os omníveros. Para os pesquisadores a influencia da socialização é menor comparada com a influência da dieta (Chen, 2017).

\subsection{O Homem e Seus Ancestrais}

É possível observar o desenvolvimento e crescimento do cérebro em relação a outros mamíferos. Estudos mostram que o crescimento das estruturas cerebrais se fez, ao longo da história humana, através da socialização, da invenção e utilização de ferramentas e da linguagem (de Leon, 2021), além da criação de estratégias para a busca de alimentos e mudanças comportamentais mediadas pela cultura (Tuttle, 2021).

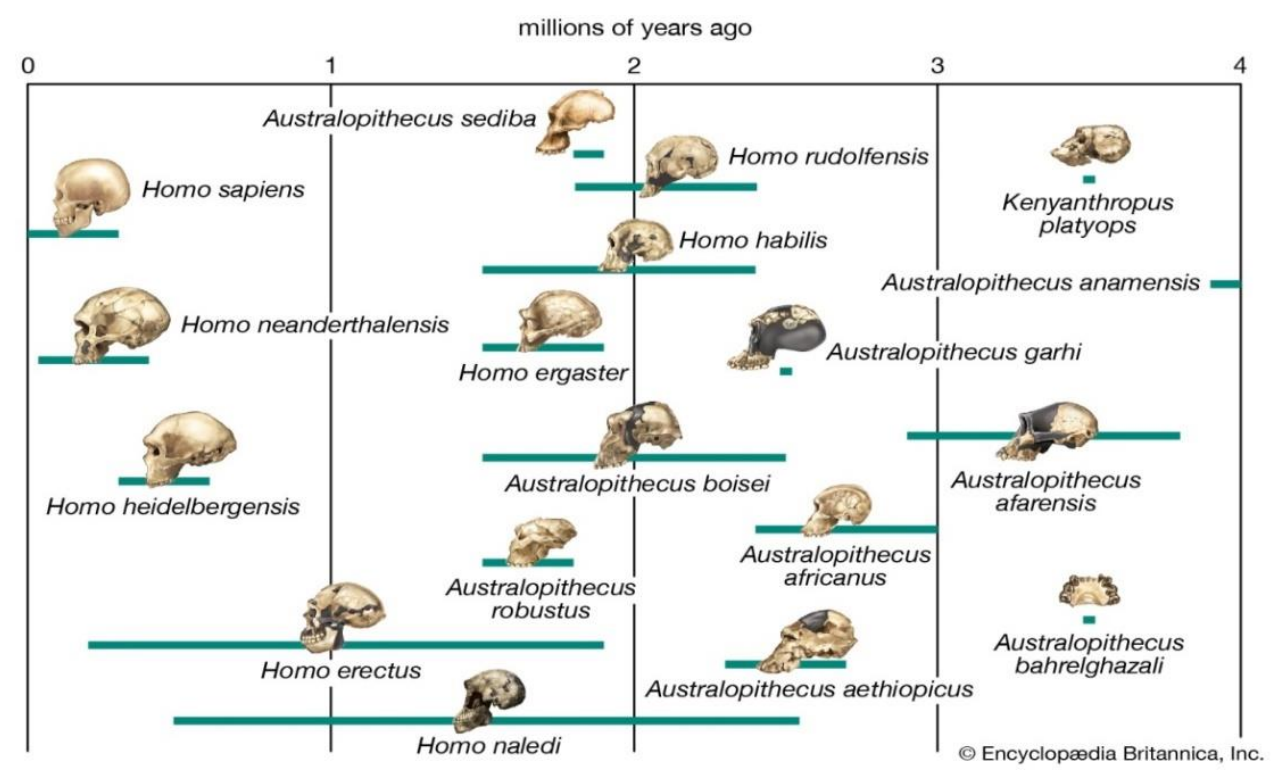

Fonte: Encyclopaedia Britannica, Inc. 
A evolução do homem não é linear e ocorre de maneira espontânea. Ao longo dos anos, o homem foi se afastando dos seus primos primatas, se adaptando ao meio e recebendo a cada geração uma herança genética. Surgiam assim várias espécies de homens que se multiplicavam e se adaptavam de diversas maneiras, dependendo do ambiente, da necessidade e da sua genética herdada.

Essas espécies viviam ao mesmo tempo em várias partes do mundo lidando com diferentes adversidades, umas sobreviveram e seguiram em frente, outras não. De todas as espécies humanas, quatro são as que apresentam as mudanças mais significativas dos estágios de evolução do homem: Australopitecus, homo habilis, homo erectus, neanderthais e homo sapiens.

Os Australopitecus e suas diversas subespécies viveram entre 4 e 1, 4 milhões de anos e possuíam proporções do corpo mais primitivas, pernas curtas e braços longos, foi o primeiro bípede dentre os ancestrais humanos. Seu cérebro era 1/3 do tamanho do cérebro do homem moderno, mais estreito e alongado, e se adaptou para reconhecer melhor rostos e sinais de perigo além de ter comportamentos sociais mais complexos.

A transição do Australopitecus para a espécie homo decorreu em grande parte das mudanças da dieta e do meio. Em busca de comida, eles desceram das árvores, saíram das florestas para as savanas e passaram a se alimentar de carne. Essas mudanças na dieta ocasionaram uma maior ingestão de nutrientes provocando o desenvolvimento maior do corpo e do cérebro (Johanson, 2018).

Após alguns anos, um novo estágio da evolução se inicia, o cérebro começa a encurtar a base na parte inferior de palato e o crânio está mais arredondado, e a capacidade de manusear objetos se torna mais precisa, assim é caracterizado o Homo Habilis.

Viveu aproximadamente entre 2 e 1,5 milhões de anos. O modo como aos membro desta espécie viviam e como se relacionavam uns com os outros não está totalmente claro e eles se apresentam como uma espécie de transição entre os australopitecus e as espécies homos mais avançadas (Rightmire, 2020).

O Homo Erectus, viveu a aproximadamente 1.9 milhões de anos, é o especialista em uma grande variedade de ambientes. É alto e veloz. Ele possui o maior cérebro entre os primatas daquela época, e seu formato é assimétrico já indicando a diferença entre os hemisférios direito e esquerdo. É descrito como o homem tecnológico, fabricante de ferramentas, viajante, com grande inteligência social, capaz de viver em grupos e 
representa o início do que seria uma linguagem, a protolinguagem (Hendry).

Os Neanderthais habitaram principalmente a Eurasia, seus ossos eram mais pesados e tinham baixa estatura. Sobreviveram a ultima era do gelo devido ao bom isolamento térmico dos seus corpos que tinham a estrutura mais similar com o homem moderno dentre a espécie o que a grande adaptação dessa espécie aos climas gelados. Tinham uma cultura de caça e eram bons na produção de ferramentas e armas (Williams, 2020).

Em relação ao crânio, este era recuado e apresentava uma protuberância occipital, uma testa e queixo baixos. Era maior ou relativamente similar em tamanho do cérebro do homem moderno. É possível que a mente dos neanderthais fosse fragmentada, ou seja, eles se concentravam em uma coisa apenas e não conseguiam fazer uma coisa e pensar outra ao mesmo tempo.

O tempo e a forma em como se deram essas mudanças que levaram a espécie homo a esse nível de evolução não possuem, entre especialistas, uma conformidade de dados. Com a falta de cérebros fossilizados, os estudos são feitos com moldes da base óssea do cérebro que mostram as diferenças entre o formato do cérebro humano atual e seus ancestrais.

Com os rostos menores, o Homo Sapiens possui um cérebro mais arredondado, parietal protuberante e com a área frontal mais íngreme, diferente dos seus ancestrais que apresentam o cérebro mais alongado e menos arredondado. Os neanderthais são os que apresentam as maiores similaridades em relação ao cérebro do homem moderno com apenas algumas diferenças e já é possível constatar que o cérebro cresceu o triplo de tamanho desde os australopithecos (os mais próximos do gênero homo ao longo da evolução) até o homo sapiens (Neeubauer, 2018; Du, 2018).

\subsection{O Esfenóide: a chave para a evolução?}

Por muitos anos os especialistas procuraram entender qual era a chave da evolução. Qual o fator, interno ou externo, foi o mais importante para explicar a transformação do homem. Muitos especialistas perceberam que a mastigação o maxilar mudava e com ele todo o crânio e esqueleto frontal conseqüência das mudanças que ocorreram nos ossos da base craniana.

A base craniana é a marca da evolução do homem. Em especial o esfenóide. Ele é um osso situado na base craniana com uma formato de borboleta e a estrutura e leveza do crânio, o formato da cavidade nasal, a mastigação, a respiração, o transporte de vários 
vasos sanguíneos e sangue do crânio até a cabeça e pescoços, a postura dos corpos e a conexão entre o crânio e o esqueleto facial estão todos relacionados a ele (Jamil, 2021).

Ele é o osso mais complexo do corpo e está localizado em um lugar escondido na base do crânio. É envolta dele que corpo e crânio se desenvolveram. Suas articulações conectam o crânio com o esqueleto da face, os ossos parietais e temporais, a parte de trás do crânio com a coluna vertebral e ele é capaz de receber as pressões da mastigação e do bipedarismo. .

Em 70 milhões de anos o esfenóide mudou e flexionou a sua estrutura cinco vezes e a cada mudança uma nova espécie da família dos hominídeos se desenvolvia o que indica que meio externo é importante para a evolução do homem, mas como influencia secundária. A essência da evolução está dentro do corpo, exatamente, na base craniana.

A primeira mudança do esfenóide ocorreu a mais de 40 milhões de anos. Foi a primeira flexão ocorreu girando a base craniana para baixo. Isso provoca uma mudança fundamental na anatomia da face trazendo os ossos para frente. Durante as próximas dobras o cérebro se torna mais complexo, o crânio muda sua estrutura novamente que começa a tomar um formato mais globular e menos plano, e a partir da terceira flexão começa o processo de verticalização do hominídeo.

$\mathrm{Na}$ quarta flexão do esfenóide um grande desenvolvimento psicomotor ocorrer permitindo ao homem não apenas a se manter ereto, mas também a andar e correr grandes distancia, possibilitando melhor a caça, a viagem e a sobrevivência. Alem disso, começam a se desenvolver o aparelho fonador e a laringe que permitiram os primeiro sinais da linguagem.

Como a quinta a dobra o crânio chega a sua estrutura mais moderna, surge o homo sapiens. Essa mudança no esfenóide é paralelo ao aumento do cérebro, maior suprimento de sangue para o cérebro, inicio do pensamento abstrato, a cultura e a arte.

Os estudos com o esfenóide e suas flexões ao longo do tempo, possibilitaram a compreensão de como esse processo de evolução se deu ao longo da história, em varias partes do mundo, de diferentes maneiras, em períodos diferentes e que esse osso, tão complexo, continua, mesmo após milhares de anos, a se "movimentar" nos corpos do homem moderno com a direção da genética e da hereditariedade (Malassé).

\subsection{O Cérebro do Homem Moderno}

Wong (2020) afirma que a capacidade de criar ferramentas, principalmente para a caça, 
permitiu que o homem tivesse acesso a melhores alimentos com nutrientes necessários para o desenvolvimento cerebral e o que fez com que o órgão triplicasse o seu tamanho. Porém, é importante salientar que o aumento do volume cerebral é apenas um dos elementos evolutivos do cérebro.

Outros elementos se apresentam observando as distinções entre o cérebro feminino e masculino. Os homens têm $30 \%$ mais conexões neuronais, $12 \%$ de maior volume do cérebro e $10 \%$ a mais no tamanho da amígdala enquanto as mulheres possuem maior fluxo sanguíneo, proporção de massa cinzenta e densidade neuronal nas regiões relacionadas a linguagem e tamanho do hipocampo. Estas diferenças se refletem em muitos comportamentos de homens e mulheres, mas não definem o nível de inteligência de ambos os gêneros (Malva, 2021).

Diante de testes não foram observadas grandes diferenças nas habilidades cognitivas entre os sexos em relação ao volume do cérebro, o que mostra que outros fatores como a complexidade cerebral, suas funções e sua estrutura interna são importantes para inteligência (Deary, 2021).

Ainda assim, é possível perceber que o órgão foi se modificando ao longo do tempo e se tornando uma estrutura complexa e auto-organizada. A inteligência foi se formando através do desenvolvimento de uma intricada rede de neurônios que se ligam uns aos outros através das sinapses levando informação para diferentes estruturas do cérebro. A interação entre essas estruturas é responsável pela alta capacidade das funções cognitivas, comunicativas e de execução (Dicke, 2016).

As transformações cerebrais não acontecem apenas durante a história humana, mas no tempo de vida de uma pessoa. $\mathrm{O}$ volume de massa cinzenta, um importante integrante do sistema nervoso central, se altera de acordo com os reajustes dos neurônios durante as sinapses. O cérebro não é uma estrutura fixa, ele muda constantemente desde a infância até a idade adulta, dependendo de vários fatores como aprendizagem, idade, experiência e diferenças hormonais (Goriounova, 2019).

Estudos mostram que existe uma correlação entre inteligência e diferentes áreas do cérebro. Dados de imagiologia cerebral mostraram que a inteligência está, em grande parte, associada com os lobos frontal e temporal e que o QI, que mede as capacidades cognitivas, está relacionado com o volume do cérebro, cerebelo, hipocampo e lobo temporal (Deary, 2021). 
De acordo com Mateos-Aparicio (2019) outra grande capacidade dos neurônios é a modificação e o fortalecimento das transmissões sinápticas reorganizando a estrutura, funções e conexões cerebrais. Essa capacidade, conhecida como neuroplasticidade não é apenas fundamental para o desenvolvimento do cérebro e recuperação das áreas cerebrais lesionadas, mas também para a memória, aprendizagem e aquisição de novas habilidades. Contudo, a neuroplasticidade tem sofrido mudanças ao longo do tempo, principalmente após o advento da internet. Mudando os hábitos diários de maneira abrupta, a internet provocou uma desconexão da realidade impedindo que as pessoas exerçam atividades fundamentais para o desenvolvimento das funções cognitivas como ler e praticar exercícios.

A facilidade de utilizar os seus recursos e a rapidez das suas operações favoreceu o surgimento de vícios e de uma dependência da internet. Sua utilização recorrente libera a dopamina que cria uma sensação de bem estar seguida de sensações de ansiedade, cansaço e frustração (Abreu, 2021).

\section{CONSIDERAÇÕES FINAIS}

O cérebro é o órgão mais complexo dos seres vivos e entre os seres humanos ele se desenvolveu em um alto nível em suas funções cognitivas. O desenvolvimento de sua estrutura, as transmissões sinápticas, a neuroplasticidade são alguns dos elementos fundamentais para a formação da inteligência que em conjunto com o meio permite que o homem obtenha faculdades importantes para a formação da inteligência.

A capacidade para se adaptar a diferentes situações, saber racionalizar e tomar as melhores decisões, reter informações importantes, fazer abstrações e se comunicar uns com os outros é o que permite a diferenciação do ser humano e o faz único em relação a outros seres vivos.

É importante destacar que a superioridade humana em relação ao outros seres vivos é subjetiva. Ela se deu pelo desenvolvimento da inteligência provocada por vários fatores ambientais presentes em cada era da existência humana. A cada necessidade uma nova habilidade. Diante disso, ser humano é similar a outros organismos que buscam o seu próprio desenvolvimento e o desenvolvimento de suas inteligências procurando conservar a existência de sua espécie. No caso dos seres humanos, o cérebro é esse pilar fundamental que mantém e defende a existência da espécie. 
Outros seres vivos encontraram suas próprias maneiras de sobreviver. Seja com o desenvolvimento do olfato, audição e visão, no aperfeiçoamento da caça, através de venenos, dente e garras, todos eles progrediram em suas habilidades para se manterem vivos, seguros e permitir a sua reprodução.

Em relação aos homens, a busca também é sobreviver e reproduzir. Em relação a outros seres vivos, o ser humano é frágil e facilmente dominado por adversidades externas. Diante das dificuldades, o homem passou a aprimorar a sua inteligência e a utilizar meios de sobreviver seja manuseando o fogo, inventando instrumentos de trabalho ou criando armas para se defender. Tudo isso permitiu ao homem superar seu estado instintivo natural e agir logicamente, refletindo e fazendo escolhas perante as dificuldades que apareciam até alcançar um estágio de tamanho avançado que a inteligência se tornou capaz de controlar estados límbicos emocionais.

Ao longo da historia, o homem foi criando diversos recursos que permitiu a ampliação da inteligência. A escrita, leitura, artes, as ciências, a filosofia e exercícios físicos foram fundamentais para o desenvolvimento cognitivo e que nos últimos anos, infelizmente, tem sido freado pela internet. Apesar de ser parte da evolução humana, a internet, repentinamente, modificou costumes e estilos de vida o que afetou também a nossa inteligência.

\section{REFERÊNCIAS}

ABREU. Fabiano de . Somos menos inteligentes desde 1970. Aventuras na História UOL- 2021. https://aventurasnahistoria.uol.com.br/noticias/fabiano-deabreu/somos-menos-inteligentes-desde-1970.phtml

ALMÉCIJA, Sergio. The Hand. Sergio Almécija 2021. http://www.sergioalmecija.com/the-hand/

Assaf, Y., Bouznach, A., Zomet, O. et al. Conservation of brain connectivity and wiring across the mammalian class. Nat Neurosci 23, 805-808 (2020). https://doi.org/10.1038/s41593-020-0641-7

BIRD, Eleanor. Human Brain is not more efficient than other mammal's brain. Medical News Today. 2020. https://www.medicalnewstoday.com/articles/human-brain-isnot-more-efficient-than-other-mammals-brains

CHAZAN, Michael. Toward a long prehistory of fire. Current Anthropology, v. 58, n. S16, p. S351-S359, 2017.https://doi.org/10.1086/691988 
CHEN, Anna. Species diet shown to affect brain size. The John Hopkins News Letter. 2017. https://www.jhunewsletter.com/article/2017/04/species-diet-shown-toaffect-brain-size

CHERRY, Kendra. Theories of Intelligence in Psychology. Very Well Mind. 2019. https://www.verywellmind.com/theories-of-intelligence-2795035

CHERRY, Kendra. Gardner's Theory of Multiple Intelligences. Very Well Mind. 2021. https://www.verywellmind.com/gardners-theory-of-multiple-intelligences2795161

CHERRY, Kendra. What Is General Intelligence (G Factor)?. Very Well Mind. 2021. https://www.verywellmind.com/what-is-general-intelligence-2795210

CHOLLET, François. On the measure of intelligence. arXiv preprint arXiv:1911.01547, 2019.

DE LEÓN, Marcia S. Ponce et al. The primitive brain of early Homo. Science, v. 372, n. 6538, p. 165-171, 2021. DOI: 10.1126/science.aaz0032

DEARY, Ian J.; COX, Simon R.; HILL, W. David. Genetic variation, brain, and intelligence differences. Molecular Psychiatry, p. 1-19, 2021. https://doi.org/10.1038/s41380-021-01027-y

DESILVA, Jeremy et al. One small step: A review of Plio-Pleistocene hominin foot evolution. American journal of physical anthropology, v. 168, p. 63-140, 2019. https://doi.org/10.1002/ajpa.23750

DICKE, Ursula; ROTH, Gerhard. Neuronal factors determining high intelligence. Philosophical Transactions of the Royal Society B: Biological $\begin{array}{lllllll}\text { Sciences, } & \text { v. } \quad 371, \quad \text { n. } & 1685, \quad \text { p. } 20150180,\end{array}$ https://doi.org/10.1098/rstb.2015.0180

DU, Andrew et al. Pattern and process in hominin brain size evolution are scaledependent. Proceedings of the Royal Society B: Biological Sciences, v. 285, n. 1873, p. 20172738, 2018. https://doi.org/10.1098/rspb.2017.2738

Gómez-Robles, A., Hopkins, W. D., Schapiro, S. J., \& Sherwood, C. C. (2015). Relaxed genetic control of cortical organization in human brains compared with chimpanzees. Proceedings of the National Academy of Sciences, 112(48), 1479914804. 
GORIOUNOVA, Natalia A.; MANSVELDER, Huibert D. Genes, cells and brain areas of intelligence. Frontiers in human neuroscience, v. 13, p. 44, 2019. https://doi.org/10.3389/fnhum.2019.00044

HENDRY, Lisa. Homo erectus, our ancient ancestor. Natural Hystory Museum. https://www.nhm.ac.uk/discover/homo-erectus-our-ancient-ancestor.html

Herculano-Houzel, S. (2009). The human brain in numbers: a linearly scaled-up primate brain. Frontiers in human neuroscience, 3, 31. https://doi.org/10.3389/neuro.09.031.2009

HOLOWKA, Nicholas B.; LIEBERMAN, Daniel E. Rethinking the evolution of the human foot: insights from experimental research. Journal of experimental biology, v. 221, n. 17, p. jeb174425, 2018. https://doi.org/10.1242/jeb.174425

Holowko, B. (2016). Why human jawbones shrink so rapidly in evolution scale?. IJO, 27(4).

Inoue, S., \& Matsuzawa, T. (2007). Working memory of numerals in chimpanzees. Current Biology, 17(23), R1004-R1005. https://doi.org/10.1016/j.cub.2007.10.027

JAMIL, Radia T.; CALLAHAN, Avery L. Anatomy, sphenoid bone. StatPearls [Internet], 2021.

Johanson, D. C. and McHenry, . Henry (2018, November 15). Australopithecus. Encyclopedia Britannica. https://www.britannica.com/topic/Australopithecus

Jardim-Messeder, D., Lambert, K., Noctor, S., Pestana, F. M., de Castro Leal, M. E., Bertelsen, M. F., ... \& Herculano-Houzel, S. (2017). Dogs have the most neurons, though not the largest brain: trade-off between body mass and number of neurons in the cerebral cortex of large carnivoran species. Frontiers in neuroanatomy, 11, 118. https://doi.org/10.3389/fnana.2017.00118

JOHNSON, Mark H.; JONES, Emily JH; GLIGA, Teodora. Brain adaptation and alternative developmental trajectories. Development and psychopathology, v. 27, n. 2, p. 425-442, 2015. doi:10.1017/S0954579415000073

LALAND, Kevin. How culture shapes human evolution. Project Syndicate. 2017. https://www.project-syndicate.org/commentary/human-evolution-culturelanguage-by-kevin-laland-2017-05 
MACDONALD, Katharine. The use of fire and human distribution. Temperature, v. 4, n. 2, p. 153-165, 2017. https://doi.org/10.1080/23328940.2017.1284637

Malassé, A. D., Martin, J. P., \& De Kerviler, E. (2000). Neural Tube, Spheno-occipital Flexion and Semi-circular Canals in Modern and Fossil Hominids. In Proceedings of 1999 Beijing International Symposium on Paleoanthropology (pp. 69-76). Dong Wei.

Malasse, A. D. (2021). Embryogeny and Phylogeny of the Human Posture 1: A New Glance at the Future of our Species. John Wiley \& Sons.

MALVA, Pamela. Afinal, existe diferença entre o cérebro masculino e feminino? $\begin{array}{lllll}\text { Aventuras } & \text { na } & \text { História } & - & \text { UOL. }\end{array}$ https://aventurasnahistoria.uol.com.br/noticias/reportagem/elas-e-eles-existediferenca-entre-o-cerebro-masculino-e-feminino.phtml

MATEOS-APARICIO, Pedro; RODRÍGUEZ-MORENO, Antonio. The impact of studying brain plasticity. Frontiers in cellular neuroscience, v. 13, p. 66, 2019. https://doi.org/10.3389/fncel.2019.00066

Mora-Bermúdez, F., Badsha, F., Kanton, S., Camp, J. G., Vernot, B., Köhler, K., Voigt, B., Okita, K., Maricic, T., He, Z., Lachmann, R., Pääbo, S., Treutlein, B., \& Huttner, W. B. (2016). Differences and similarities between human and chimpanzee neural progenitors during cerebral cortex development. eLife, 5, e18683. https://doi.org/10.7554/eLife.18683

MORGAN, Michael H.; CARRIER, David R. Protective buttressing of the human fist and the evolution of hominin hands. Journal of Experimental Biology, v. 216, n. 2, p. 236-244, 2013. https://doi.org/10.1242/jeb.075713

NEUBAUER, Simon; HUBLIN, Jean-Jacques; GUNZ, Philipp. The evolution of modern human brain shape. Science advances, v. 4, n. 1, p. eaao5961, 2018. DOI: 10.1126/sciadv.aao5961

Premack D. (2007). Human and animal cognition: continuity and discontinuity. Proceedings of the National Academy of Sciences of the United States of America, 104(35), 13861-13867. https://doi.org/10.1073/pnas.0706147104

Rightmire, G. Philip (2020, November 12). Homo habilis. Encyclopedia Britannica. https://www.britannica.com/topic/Homo-habilis 
Robert L. Perlman, Mouse models of human disease: An evolutionary perspective, Evolution, Medicine, and Public Health, Volume 2016, Issue 1, January 2016, Pages 170-176, https://doi.org/10.1093/emph/eow014

RODRIGUES, Fabiano de Abreu. DWRI Intelligence and Other Intelligences. International Journal of Development Research Vol. 11, Issue, 01, pp. 4357643584, January, 2021 https://doi.org/10.37118/ijdr.20911.01.2021

ROTH, Gerhard. Convergent evolution of complex brains and high intelligence. Philosophical Transactions of the Royal Society B: Biological Sciences, $\quad$ v. 370, n. 1684, p. 20150049, 2015.https://doi.org/10.1098/rstb.2015.0049

SANDGATHE, Dennis M.; BERNA, Francesco. Fire and the Genus Homo: An introduction to supplement 16. Current Anthropology, v. 58, n. S16, p. S165S174, 2017. https://doi.org/10.1086/691424

Sato, N., Tan, L., Tate, K. et al. Rats demonstrate helping behavior toward a soaked conspecific. Anim Cogn 18, 1039-1047 (2015). https://doi.org/10.1007/s10071015-0872-2

SIMMS, Chris. DNA The molecule that contains your unique genetic code and enables life itself to exist, New Scientist. https://www.newscientist.com/definition/dna/

Smaers, J. B., Rothman, R. S., Hudson, D. R., Balanoff, A. M., Beatty, B., Dechmann, D. K., ... \& Safi, K. (2021). The evolution of mammalian brain size. Science Advances, 7(18), eabe2101.

D OI: $10.1126 /$ sciadv.abe2101

The Human Journey. Genetics and Human Evolution. https://humanjourney.us/genetics-and-humanevolution/?gclid=EAIaIQobChMIvt7ztMf58wIVaG1vBB3WGAmHEAAY AiAAEgJ3MfD_BwE

TUTTLE, Russell Howard.Human Evolution. Britannica, 2021.https://www.britannica.com/science/human-evolution

WEDER, Annika. Q\&A - What is Intelligence. Johns Hopkins Medicine. 2020. https://www.hopkinsmedicine.org/news/articles/qa--what-is-intelligence

Williams, F. L'Engle , Tuttle, . Russell Howard and Trinkaus, . Erik (2020, February 6). Neanderthal. Encyclopedia Britannica. 
https://www.britannica.com/topic/Neanderthal

WONG, Kate. How Scientists Discovered the Staggering Complexity of Human Evolution. Scientific American. 2020.

https://www.scientificamerican.com/article/how-scientists-discovered-the-staggeringcomplexity-of-human-evolution/ 